\title{
MERCADERÍA ENTRE COMEDIANTES A LA LUZ DE UN DOCUMENTO DE 1608
}

\author{
Miguel GonZÁlez DENGRA \\ Centro Asociado de la UNED. \\ Úbeda
}

Hace algunos años inicié, en relación con la actividad y el espectáculo teatrales desarrollados en Úbeda durante los siglos XVI y XVII, el rastreo de los fondos documentales existentes en el Archivo Histórico Municipal de la ciudad. Poco a poco, este lento y minucioso, pero también apasionante trabajo va dando los frutos deseados. Una buena muestra de ello es el documento que, recientemente, hemos encontrado en el Fondo de Protocolos Notariales del mismo ${ }^{1}$ y que ahora presento. De esta manera, rescatados del abrigo de los legajos depositados en las rancias baldas del Archivo ubetense, van viendo la luz paulatinamente datos fidedignos que permitirán fijar, en la medida de lo posible, cuál fue la realidad histórica del teatro áureo en la citada ciudad andaluza.

Ahora bien, si en los trabajos redactados con anterioridad los diversos documentos que allí se aportaban hacían referencia, entre otros asuntos, a los espacios escénicos existentes en la ciudad andaluza en el siglo XVII, a una compañía de comediantes que recaló por ella en 1643 o al pleito entablado por la Compañía de Jesús contra una cofradía por el uso de un lugar sagrado para llevar a cabo representaciones ${ }^{2}$, el interés del documento

1 He de decir, en honor a la verdad, que he contado siempre en estos trabajos con la colaboración inestimable de mi colega en el Centro Asociado de la UNED en Úbeda Vicente Miguel Ruiz Fuentes, funcionario del citado Archivo.

2 Véanse mis artículos siguientes: «Algunas noticias acerca del teatro en Úbeda en el Siglo de Oro», en Actas de las II y III Jornadas de Humanismo y Renacimiento, José LATORRE Garcf́a (ed.), Úbeda, Centro Asociado de la UNED, 1996, pp. 395-410; «Datos para la reconstrucción de la vida teatral del Siglo de Oro en Úbeda», en Mira de Amescua en candelero, Actas del Congreso Internacional sobre Mira de Amescua y el teatro español del siglo XVII, Agustín DE LA GRANJA, y Juan Antonio MARTíNEZ BERBEL (eds.), Granada, Universidad, 1996, vol. II, pp. 223-237; y «Pleito entre la Compañía de Jesús y la Cofradía de Santa Catalina de Úbeda acerca de una propiedad en la que se hacían representaciones», en El escritor y la escena IV, Ciudad Juárez, Universidad, 1996, pp. 137-146. 
que ahora publico se debe a causas bien distintas, que, como se podrá leer más adelante, no son, sin embargo, menos importantes que las referidas en los trabajos ya publicados.

El documento, que se transcribe íntegramente, está fechado en la ciudad de Úbeda el día 18 de agosto de 1608, y corresponde a los realizados por el escribano Juan de Cotillas ${ }^{3}$. Cuenta el mismo con dos partes claramente diferenciadas: en la primera de ellas, se recoge la comparecencia de un tal Juan de la $\mathrm{Cruz}^{4}$ ante el escribano público de Úbeda para dar cuenta de una serie de obligaciones económicas que, con anterioridad, tiene contraídas, así como de las que otros, que resultan ser comediantes, tienen con él; en la segunda, se realiza la relación completa del contenido de cuatro cajas que tiene en su poder Juan de la Cruz y que encierran las pertenencias de una compañía de comediantes. Debido a la nítida diferencia de ambas partes, las tranșcribiré y las estudiaré por separado.

El documento del escribano Juan de Cotillas, en lo que se refiere a la primera parte, reza de la siguiente manera:

«En la ciudad de Úbeda, en diez y ocho días del mes de agosto de mil y seiscientos y ocho años, ante mí el escribano publico y testigos de yuso escritos pareció Juan de la Cruz, que ansí se dijo llamar y ser vecino de la çiudad de Sanlúcar, y dijo que por cuanto Alonso de Heredia, autor de comedias, vecino de la villa de Madrid, le debe cinco mil y cuatrocientos y setenta reales por obligaçión ante Alonso Martínez, escribano de la dicha ciudad de Sanlúcar, su fecha a nueve de junio de este dicho año, y fecha cuenta entre ellos de todo lo que le ha dado hasta hoy día a cuenta de la dicha obligaçión, le resta debiendo cuatro mil ochenta y dos reales y queda pagado de todos sus salarios y costas hasta entrar en Sanlúcar y lo que ha recebido son mil y trescientos y ochenta y ocho reales, y en la dicha cantidad entra y se comprenden veinte ducados que Pedro Montero, escribano publico de la ciudad de Granada, (que) le tiene de dar por cédula que el dicho Alonso de Heredia le ha dado y de la cantidad recebida al pie de la dicha obligación hay razón y carta de pago para más claridad, y agora, por causas que le mueven, dijo que de su voluntad hacía e hiço espera al dicho Alonso de Heredia por los dichos cuatro mil y ochenta y dos reales de aquí a ocho días de el mes de junio primero que vendrá para que el dicho día se los pague, dejando como deja la dicha escritura de obligaçión en su fuerza y vigor, para en virtud de ella o de esta cobrar la dicha deuda, en resguardo de la cual el dicho Alonso de Heredia y María de Rojas, su mujer, le entregan un memorial escrito en dos hojas, firmado de Pedro de Valdés y Jerónima de Burgos, su mujer, y firmado del presente escribano, hecho en Valladolid, a doce de julio de mil y seiscientos y siete, para que todos los bienes en el contenidos se los den y

3 Legajo 763, folios 394-r al 400-v del Fondo de Protocolos Notariales del Archivo Histórico Municipal de Úbeda.

4 No he encontrado, hasta el momento, referencias que aclaren si se trata de algún actor de comedias o, al menos, si este Juan de la Cruz era alguien relacionado, directa o indirectamente, con el mundo de la farándula de finales del siglo XVI o principios del XVII. 
entreguen, con que al dicho Pedro de Valdés se le paguen y satisfagan dos mil y tantos reales que el dicho Alonso de Heredia y su mujer le deben por obligaçión de mayor contía ${ }^{5}$ (sic.) de manera que será la dicha deuda dos mil y trescientos sobre poco más o menos, y el dicho Juan de la Cruz ha de recebir todos los bienes y hato contenido en el dicho memorial que se le entrega original con cuenta y razón, por ansí lo que está en la dicha memoria, como lo demás que se hallare en las cajas, ropa, oro, plata y otras cosas que el dicho Pedro de Valdés tiene en su poder en las dichas cajas e recebido el dicho hato el dicho Juan de la Cruz lo ha de llevar lo ha de llevar [sic. repetición] a la ciudad de Sanlúcar dentro de dos meses y tenello en custodia y guarda hasta ser cumplido el dicho tiempo y ha de llevar consigo testimonio de todo lo que entrego y guardo por ante nos y por este lo ha de entregar al dicho Alonso de Heredia pagándole ante todas cosas los dichos cuatro mil y ochenta y dos reales y más lo que el dicho Juan de la Cruz pagare al dicho Pedro de Valdés y si no le diere y entregare los dichos bienes y cuentas de ellos que le pagara su valor con costas e intereses con sólo su firma, sin otra averiguación y de esta manera se obligo de lo cumplir y se lo ha de pagar lo que costare llevar el dicho hato dende Valladolid hasta Sevilla con lo demás. Y estando presentes los dichos Alonso de Heredia y María de Rojas, su mujer, vecinos de la villa de Madrid, y la susodicha en presencia y con licencia que el dicho su marido le dio y ella se la pidió y se obligó de la haber por firme y ambos a dos juntamente y en mancomunión y a voz de uno, renunciando [a] las leyes de la mancomunidad, división y [re]percusión como en ella se contiene. A[d]juntaron la tal escritura como en ella se contiene y dieron poder cumplido que al derecho se requiere y más que da valor al dicho Juan de la Cruz para que pueda pedir e demandar e recebir, haber y cobrar del dicho Pedro de Valdés y de otras personas y de quien con derecho deba todos los bienes contenidos en el dicho memorial, que le entregan original en presencia de mí el escribano y testigos de que doy fe juntando que el dicho memorial queda justamente con esta escritura [siguen las fórmulas legales usuales]».

Según se puede deducir del manuscrito del escribano Juan de Cotillas, el matrimonio formado por los actores Alonso de Heredia ${ }^{6}$ y María de Rojas ${ }^{7}$ tiene contraída una deuda, por un lado, con el matrimonio constituido por los también cómicos Pedro de Valdés ${ }^{8}$ y Jerónima de Burgos ${ }^{9}$ la

\footnotetext{
5 «Cuantía».

6 Alonso de Heredia era ya autor de comedias en 1603, representando con su importante compañía autos en Madrid en 1609 y viviendo aún en 1638. Junto a Pedro de Valdés y otros fue de los autores de comedias a los que el decreto de 1615 dio autorización exclusiva para llevar a cabo representaciones de comedias en España durante dos años. (Véase Hugo A. RENNERT, The Spanish Stage in The Time of Lope de Vega, Nueva York, 1909, p. 491, así como Américo CASTRo y Hugo A. RENNERT, Vida de Lope de Vega, Madrid, Anaya, 1968).

Se casó con Alonso de Heredia en 1604 (RENNERT, op. cit., p. 580 y CASTRo y RENNERT, op. cit., p. 214).

8 Famoso actor y autor de comedias, cuya reputación fue de las más importantes del siglo XVII. (RENNERT, op. cit., pp. 612-613).

9 Famosa actriz, nacida, probablemente en Valladolid, hacia 1580, fue amiga y amante de Lope de Vega, quien la llamó «amiga del buen nombre». El 7 de febrero de
} 
MIGUEL GONZÁLEZ DENGRA

cantidad, en reales, de «dos mil y trescientos sobre poco más o menos»; $\mathrm{y}$, por otro, con el citado compareciente Juan de la Cruz, vecino de Sanlúcar, «cinco mil y cuatrocientos y setenta reales por obligación (...) a nueve de junio» de 1608, dada en Madrid, como se puede observar, dos meses y nueve días antes que la fecha del documento ubetense. De dicha obligación, el afectado había recibido en aquel momento «mil y trescientos y ochenta y ocho reales». De todo ello resulta que, ante el escribano Juan de Cotillas, y "por causas que le mueven, [Juan de la Cruz] dijo que su voluntad hacía e hiço espera al dicho Alonso de Heredia por los dichos cuatro mil y ochenta y dos reales de aquí a ocho días de el mes de junio primero que vendrá para que el dicho día se lo pague».

Quiere esto decir que el citado Juan de la Cruz aguardará a recibir la diferencia restante de lo que le adeudan Alonso de Heredia y María de Rojas hasta el 8 de junio de 1609, fecha en la que se cumplirá un año desde la firma de la obligación original, valorada en cinco mil cuatrocientos setenta reales y que fue realizada por el matrimonio de actores.

Por otra parte, y respecto a la relación profesional entre los comediantes Alonso de Heredia y Pedro de Valdés, ésta debió ser buena en aquellos años iniciales del siglo XVII, a tenor de lo que transcribe Luis Fernández Martín de un documento de la época en el que reza la finalización del consorcio que ambos actores habían tenido, por lo que tenían que repartirse las comedias que hubieran comprado mientras que duró su asociación ${ }^{10}$.

Pero la cuestión que plantea el documento del Archivo Histórico de Úbeda aquí presentado es más compleja. Alonso de Heredia y María de Rojas, previendo, probablemente, que no podrían hacer frente, en tiempo y forma, a la deuda que tenían adquirida con Pedro de Valdés y Jerónima de Burgos, se comprometieron, de forma mancomunada, en Valladolid el día doce de julio de 1607 (es decir, trece meses antes de la fecha de nuestro documento) a hacer efectiva la misma no en dinero, sino en especie, mediante la entrega de todo el equipaje que, repartido en cuatro cajas, contenía el hato de una (su) compañía de comediantes. Como se puede observar, el matrimonio de actores tenía consciencia del valor económico del ajuar de la compañía y no dudó, ante la imposibilidad, probablemente, de hacerlo en efectivo, en pagar la deuda que tenía contraída con el con-

1607 actuó de madrina del bautizo del hijo habido entre el poeta y Micaela Luján, siendo el padrino Juan Andrés Hurtado de Mendoza. Jerónima de Burgos, pese a estar casada con Pedro de Valdés, formó parte de la compañía de Alonso de Riquelme y de la de Cristóbal Ortiz. Para ella, escribió LOPE La dama boba. Murió, viuda, en Madríd, el 27 de marzo de 1641. (RENNERT, op. cit. y CASTRO y RENNERT, op. cit.).

10 Luis FERNÁNDEZ MARTín, Comediantes, esclavos y moriscos en Valladolid. Siglos XVI y XVII, Valladolid, Universidad, 1988, p. 68. Cojo la cita de José María RUANO DE LA HAZA y John J. ALLEN, Los teatros comerciales del siglo XVII y la escenificación de la comedia, Madrid, Castalia, Nueva Biblioteca de Erudición y Crítica, 1994. 
tenido de las cajas. Posteriormente, Heredia adquiere una nueva obligación, en este caso con Juan de la Cruz, el cual se lleva consigo todo el equipaje, que, en realidad y según se desprende de la obligación anterior, es propiedad de Pedro de Valdés y de Jerónima de Burgos. Juan de la Cruz ha de transportar las cajas de Valladolid a Sevilla, como aval de lo que posteriormente ha de cobrar del propio Heredia ${ }^{11}$.

Detengámonos, ahora, en llevar a cabo el análisis de la segunda parte de este documento del escribano Juan de Cotillas, en la que, como ya se ha dicho, se recogen los bienes relacionados en la memoria que aparece anexa al mismo. Se trata de la explicación detallada del contenido de las cuatro cajas que transportaba el referido Juan de la Cruz y que guardaban el vestuario y los útiles suficientes para que una compañía de actores del siglo XVII pudiera llevar a cabo las representaciones teatrales. Esta parte, textualmente, dice:

«Memoria de lo que queda en este arca primera: dos pares de calzones de tafetán, dos botargas ${ }^{12}$ azules, un sayo de damasco azul con jirones carmesíes, otro sayo de damasco azul con pasamanos ${ }^{13}$ de plata, otro sayo de raso pajizo con jirones de damasco carmesí, un sayo de raso azul con jirones naranjados, un sayo de brocatel ${ }^{14}$ pajizo e leonado, otro sayo de brocatel encarnado, otro sayo de brocatel blanco y pajizo, otro sayo de brocado verde fino, otro sayo de damasco verde con jirones de primavera ${ }^{15}$ encarnada, otro sayo de raso naranjado con jirones de damasco carmesí, otro sayo naranjado con jirones de terciopelo morado (fondo en oro), otro sayo de damasco azul dorado con jirones de brocado encarnado fino, otro sayo de damasco azul y dorado con jirones de raso de oro encarnado, guarnecido de oro fino, una ropa de brocatel blanca y dorado con vueltas de primavera pajizas, otra ropa de bro-

11 Pese a lo dicho por Rennert (en Vida de Lope de Vega, p. 168: «Éste último [Pedro de Valdés] se casó con ella [Jerónima de Burgos] hacia el 14 de febrero de 1614») el presente documento vendría a confirmar algo ya sabido: que ambos formaban matrimonio en 1607, como confirman las adiciones de Américo Castro en el mismo libro (p. 535): «La boda de Jerónima de Burgos con Pedro de Valdés tuvo lugar antes: en enero de 1603 se había celebrado ya el matrimonio).

12 «Una parte del traje que se traía antiguamente, que cubría el muslo y la pierna y era ancha» o «vulgarmente se llama hoy un vestido ridículo, que sirve de disfraz, y es todo de una pieza, que se mete por las piernas, y después entran los brazos, y se abotona con unos botones gordos. Está hecho de varios colores casados en contrario para causar risa a los circunstantes». Todas las definiciones que aparecen como notas, salvo indicación en sentido contrario, están sacadas del Diccionario de Autoridades.

${ }_{13}$ «Se llama también un género de galón o trencilla de oro, plata, seda o lana que se hace y sirve para guarnecer y adornar los vestidos y otras cosas por el borde o canto».

14 «Cierto género de tejido de hierba 0 cáñamo y seda, a modo de brocato [brocado] o damasco, de que se suelen hacer colgaduras para el adorno de las iglesias, camas y otras cosas».

15 «Cierto género de tela o tejido de seda, sembrada y matizada de flores de varios colores, por cuya razón se le dio este nombre». 
catel encarnado con vueltas de tafetán, todo lo cual es nuevo, un repostero ${ }^{16}$ nuevo, un justillo ${ }^{17}$ azul.

Memoria de lo que esta en la segunda arca: una botarga azul, un envoltorio con unos pedazos de brocado fino y otros de brocatel y tafetán azul, cuatro ropillas y calzones de lienzo pintados, diez monteras ${ }^{18}$ de brocatel con sus toquillas de pasamanos falsos, ocho máscaras, dos capellares ${ }^{19}$ de tafetán blanco, dos marlotas ${ }^{20}$ de tafetán encarnado, otra marlota y capellar de tafetán blanco y verde, dos tunicelas ${ }^{21}$ de tafetán pajizo, una tunicela de primavera blanca y naranjada, otra tunicela de primavera morada y dorada, otra tunicela de primavera blanca y encarnada, un almaizar ${ }^{22}$ de moro, un pelliço ${ }^{23}$ morado, otro pelliço de cabritillas, tres pendones de tafetán, unos calzones de tiritaña ${ }^{24}$, un sayo de raso negro, un lío de barbas y cabelleras y otras zarandajas, un capillo de bocaci ${ }^{25}$ negro, dos toneletes, un repostero nuevo, un justillo azul.

Memoria de lo que queda en la tercera arca: una caja de sombreros en que van diez bonetes de moros nuevos, dos gorras de terciopelo y otras menudencias, una caperuza de damasco, tres diademas, otra caperuza de raseta, dos almalafas ${ }^{26}$ de moros, dos vestidos de momio ${ }^{27}$, seis caperuzas, digo, seis capirotes $^{28}$ de frisa ${ }^{29}$ azul, otro envoltorio con unos escapularios, dos sayos

16 «Se llama también un paño cuadrado con las armas del príncipe o Señor, el cual sirve para poner sobre las cargas de las acémilas y también para colgar en las antecámaras».

17 «Vestido interior ajustado al cuerpo a modo de jubón, de quien se diferencia en no tener mangas».

18 «Cobertura de la cabeza, con un casquete redondo, cortado en cuatro cascos, para poderlos unir y coser más fácilmente, con una vuelta o caída alrededor, para cubrir la frente y las orejas».

19 «Especie de manto que suelen sacar los moros en el juego de las cañas, el cual cubre y adorna la cabeza».

20 «Cierta especie de vestidura morisca, a modo de sayo vaquero, con que se ciñe y aprieta el cuerpo. Es traje que se conserva para algunos festejos».

${ }_{21}$ «Se llama una vestidura episcopal, a modo de dalmática, con sus mangas, que se aseguran con unos cordones. Úsase en los pontificales debajo de la casulla».

22 «Toca de gasa que los moros usaban en la cabeza por gala. Era listada de colores y con rapacejos ['el flueco liso y sin labor particular'] y fluecos ['cierto género de pasamano tejido, con los hilos cortados por un lado, que se hace de hilo, lana, seda u otra cosa, y sirve de guarnición en los vestidos u otras ropas, pegándole a las orillas'] que adornaban los extremos, para que colgando éstos de la cabeza sirviesen de mayor adorno y gala».

23 «El zamarro del pastor u otro vestido de pieles hecho a semejanza de él».

24 «Tela de seda delgada».

25 «Tela de lino de varios colores, especialmente negro, encarnado o verde, que parece está engomado por lo tieso. Es más gordo y basto que la holandilla».

26 «Especie de manto o ropa que usaban las moras y se ponía sobre todo el demás vestido, y comúnmente era de lino».

27 «Magro y sin gordura».

28 Resulta curiosa la confusión que tiene el escribano entre 'caperuza' y 'capirote', ya que la diferencia entre ambos, según Autoridades, es mínima: caperuza «cobertura de la cabeza o bonete, que remata en punta inclinada hacia atrás»; capirote "cobertura de la cabeza, que está algo levantada y como que termina en punta».

29 «Tela de lana, a modo de bayeta, aunque más corpulenta, que sirve para aforos y para otros usos». 
de villanos, dos capas cortas de rasa, un coleto ${ }^{30}$ amarillo, un coleto de ante, un calzón de damasco azul, otro calzón de raso azul con un pasamanos de oro fino, un calzón y ropilla de tela fino negro ${ }^{31}$, un calzón de raso morado fino, un calzón de terciopelo negro bordado fino, un calzón de raso leonado guarnecido de oro fino, un jubón ${ }^{32}$ de tela fino de hombre, otro jubón de gurbión ${ }^{33}$ negro, un envoltorio con pasamanos falsos, un capotillo $^{34}$ de rasa azul, unas pieles, dos carpetillas ${ }^{35}$, un justillo azul, un repostero nuevo.

Memoria de lo que va en esta cuarta arca: un atado de lienzo con diez y ocho pañuelos y dos varas y media de lienzo de Flandes, y dos pares de medias de seda y sus ligas, tres cordones de San Francisco, una correa de San Agustín guarnecida de plata, y otras niñerías, unas pieles, dos pares de chapines ${ }^{36}$ guarnecidos de plata, tres sábanas de ruán ${ }^{37}$, tres tablas de manteles, seis servilletas alemaniscas ${ }^{38}$, dos paños de manos, una camisa de Holanda de mujer, un papel de tocas nuevas, un manto nuevo de Granada, envuelto en un tafetán verde, una basquiña ${ }^{39}$ de chamelote ${ }^{40}$ negro, otra basquiña de picote ${ }^{41}$ de seda guarnecida de oro, otra basquiña de piel de rata, un vestido de tiritaña verde, ropa, (y) saya y cuerpos, un vestido entero de mujer de tafetán negro, un vestido entero de bayeta, un vestido de rasa molinera con su escapulario e mangas, unas mangas de tafetán negro, un jubón de raso negro de mujer, otro jubón de tela fina de mujer, otro jubón de raso azul (a)trencillado de plata,

30 «Vestidura como casaca o jubón, que se hace de piel de ante, búfalo u otro cuero. Los largos como casacas tienen mangas y sirven a los soldados para adorno y defensa, y los que son de hechura de jubón se usan también para la defensa y abrigo».

${ }_{31}$ Obsérvese que la concordancia de estos dos adjetivos se hace con 'calzón' y no con 'ropilla' o 'tela'. Esta concordancia se va a reproducir varias veces a lo largo del documento.

32 «Vestido de medio cuerpo arriba, ceñido y ajustado al cuerpo, con faldillas cortas, que se ataca por lo regular con los calzones».

33 «Cierta especie de tela de seda, de torcidillo u cordoncillo».

34 Puede tener, de acuerdo con Autoridades, varios significados: 1. «Capote». 2. «Se llama también un género de muceta abierta por los lados, de que usaban antiguamente las mujeres para abrigo». 3. «Se llama también el hábito que la Santa Inquisición pone a los que penitencia».

35 Diminutivo de carpeta: «Cubierta de badana aderezada, que se pone sobre las mesas para más aseo y limpieza, la cual está dada de color; y también se llama así la que es de seda o paño, u de otra materia tejida».

36 «Calzado propio de mujeres, sobrepuesto al zapato para levantar el cuerpo del suelo; y por esto el asiento es de corcho, de cuatro dedos o más de alto, en que se asegura al pie con unas corregüelas o cordones. La suela es redonda, en que se distingue de las chinelas».

37 «Especie de lienzo fino, llamado así por el nombre de la ciudad de Ruan (sic.) en Francia, donde se teje y fabrica».

38 «Cosa perteneciente a Alemania (...); se apropia a cierto género de mantelería fabricada y tejida a cuadraditos, algo mayores que la que se llama de gusanillo».

39 «Ropa o saya que traen las mujeres desde la cintura al suelo, con sus pliegues, que hechos en la parte superior forman la cintura, y por la parte inferior tiene mucho vuelo".

40 «Tela tejida de pelo de camello».

41 «Cierta tela de seda muy lustrosa de que se hacen vestidos». 
un manteo ${ }^{42}$ de grana, un capillo de grana guarnecido de oro, unos escapularios, y tres pares de puños, un reboçiño ${ }^{43}$ de gorgarán ${ }^{44}$ negro con un pasamano de oro, un escritorio cerrado con lo siguiente: una gargantilla de aljófar ${ }^{45}$ con seis anus deis y un Cristo, unas manillas de aljófar y granates, seis sortijas de oro con piedras finas, un relicario de oro con un humilladero de cristal, un librico de oro, un anus dey de oro pequeño, un anus dey de oro pequeño ${ }^{46}$, una mano de ébano guarnecida de oro, unas arrocadas ${ }^{47}$ de oro, dos bandas de oro, dos cabestrillos y otras niñerías, un relicario guarnecido de plata, un farol de plata, un frasquillo de plata, un barquillo y una salvilla ${ }^{48}$ de plata, veintiséis botones y un corve ${ }^{49}$ de plata, un clavo de plata, treinta botones de metal dorados, dos cucharas de plata, una sarta de ámbar fina, un repostero.

Todo lo cuál me entrego en ello yo, Pedro de Valdés y Jerónima de Burgos, y daré a la persona que estas memorias truxere con poder de los dichos Alonso de Heredia e María de Rojas y por de nuestros nombres. Fecha en Valladolid a doce de julio de mil y seiscientos y siete.

Pedro de Valdés Jerónima».

Como se puede observar, por la descripción exhaustiva que se hace en el documento ubetense, las cajas propiedad del matrimonio de actores formado por Pedro de Valdés y de Jerónima de Burgos contenían el vestuario y los enseres suficientes para realizar representaciones teatrales. En la primera caja, se reunían una serie de prendas de vestir de distintos tipos, aunque con predominio de los sayos; en la segunda, distintos tipos de tocados para la cabeza, amén de cierta ropa; la caja que hace la número tres contenía, igualmente, distintas prendas para la cabeza, diferentes tipos de pantalones y algunas piezas de uso doméstico; finalmente, la cuarta caja incluía diversos tipos de calzado y enseres varios para poder representar diferentes escenas. Conviene hacer notar que las descripción del contenido de cada una de las cajas acaba siempre con un repostero.

Conocida es la importancia que para la escenificación de las comedias tuvo en aquella centuria el vestuario teatral, que llegó a alcanzar en algu-

42 «La capa que traen los eclesiásticos, que tiene sólo un cuellecito angosto de dos o tres dedos, y les cubre hasta los pies».

43 «Mantilla o ropa corta de que usan las mujeres para cubrir el bozo».

44 «Tela de seda con cordoncillo, sin otra labor por lo común, aunque también los había alistados y realzados».

45 «Especie de perla».

46 En el documento de 1608 que presento, la expresión está, como transcribo, repetida, por lo que se puede entender que hay un error del escribano o bien que realmente en el escritorio anotado en el memorial había dos agnusdeis. Obsérvese, por otra parte, lar irregularidades gráficas de esta última palabra.

47 «Cosa que tiene figura o se parece a la cabeza de la rueca».

48 «Pieza de plata o estaño, vidrio o barro, de figura redonda, con un pie hueco sentado en la parte de abajo, en la cual se sirve la bebida en vasos, barros».

49 En Autoridades no aparece tal palabra, si bien corvo significa 'garfio', por lo que podría ser una errata del que escribió el memorial. 
nas ocasiones, como muy bien ha estudiado Ruano de la Haza, un coste económico muy importante ${ }^{50}$. El mismo recoge un dato que no deja de ser curioso en comparación con el documento que aquí se presenta tanto por la proximidad de las fechas de ambos como por tratarse de dos comediantes que trabajaban bajo las órdenes de Alonso de Heredia y que es el siguiente: «en 1606 Juan Bautista de Angulo y Clara Eugenia de Torres, de la compañía de Alonso de Heredia, desembolsaron »mil reales por razón de un vaquero de terciopelo morado forrado, guarnecido y plateado todo de pasamanos de oro fino de Milán y de una saya y ropa y corpiño de raso de oro encarnado guarnecido de pasamanos de oro fino de Milán»» ${ }^{51}$.

Además, teniendo en cuenta la importancia que daban los actores del XVII a todo lo relacionado con el vestuario y el aprecio que a éste tenían, no extraña que hicieran uso de él para empeñarlo cuando se encontraran ante una situación económica difícil ${ }^{52}$. ' $\mathrm{Y}$ eso es, precisamente, lo que hicieron el matrimonio formado por Alonso de Heredia y María de Rojas: empeñar su vestuario. No sabemos - ni lo podremos saber nunca- si lo que aparece relacionado en el memorial de este documento del Archivo Histórico de Úbeda incluía todo el ajuar que usaba la compañía de Alonso de Heredia en aquel momento o, tan sólo, constituía una parte de él. Sea como fuere, lo que no cabe duda es que lo relacionado formaba un conjunto amplio y suficiente para poder representar piezas teatrales.

Lo que, por otra parte, resulta curioso en el caso del documento de Úbeda es que Alonso de Heredia y María de Rojas llevan a efecto el empeño de su ajuar teatral por dos veces: primero, para pagar la deuda que tienen contraída con Pedro de Valdés y Jerónima de Burgos; después, para que el mismo sirva como pago a Juan de la Cruz. El montante del empeño, que cubre el total de la deuda de Heredia con Valdés, es, tal y como se indica en el texto ubetense, de «dos mil y trescientos [reales] sobre poco más o menos». Una fácil observación nos permitirá concluir que el valor que Alonso de Heredia y María de Rojas daban a este vestuario teatral era bastante importante, sobre todo si tenemos en cuenta que el precio que se pagaba por el texto de una comedia apenas superaba los cien reales.

so José María RUANo DE LA HAZA y John J. ALLEN, Los teatros comerciales del siglo XVII y la escenificación de la comedia, Madrid, Castalia, Nueva Biblioteca de Erudición y Crítica, 1994. Para el tema del vestuario y el hato de las compañías, véase las páginas 295 a 299.

51 Ibídem, p. 297.

52 RENNERT, op.cit., pp. 104-110. 